\title{
Gypsum amendment as a means to reduce agricultural phosphorus loading: an economic appraisal
}

\author{
Antti Iho ${ }^{1}$ and Marita Laukkanen ${ }^{2}$ \\ ${ }^{1}$ MTT Agrifood Research Finland, Economic Research, Latokartanonkaari 9 Fl-00790 Helsinki \\ ${ }^{2}$ Government Institute for Economic Research, P.O.Box 1279 FI-00101 Helsinki \\ e-mail: marita.laukkanen@vatt.fi
}

\begin{abstract}
This study analyzes the economic feasibility of gypsum amendment as a means to reduce particulate and dissolved phosphorus loads from arable areas. To this end, an optimization model is developed that includes gypsum amendment as well as matching phosphorus fertilization to crop need and the level of soil phosphorus reserves as phosphorus load mitigation measures, with soil phosphorus reserves measured by soil test phosphorus (STP). The optimal extent of gypsum amendment is then determined simultaneously with optimal fertilization use as a function of field STP level. The results indicate that whether or not gypsum amendment is economically feasible depends on field erosion susceptibility and STP level. When accounting for the costs and benefits to the society on the whole, gypsum treatment suits best to mitigation of phosphorus losses from soils with excessively high phosphorus reserves; once a threshold STP level is reached, gypsum amendment is optimally given up. This threshold level depends on field slope and on society's willingness to pay for water quality.
\end{abstract}

Key words: dynamic optimization, phosphorus fertilization, gypsum amendment, phosphorus loading, eutrophication.

\section{Introduction}

One of the key environmental concerns today is eutrophication of surface waters, or excessive growth of aquatic plants stimulated by elevated concentrations of nitrogen and phosphorus (P) (see e.g. Rodhe 1969, OECD 1982, Solow 2000). Many environmental assessments identify agriculture as the major cause of surface water quality problems in developed countries (Shortle and Abler 1999). In particular phosphorus loading originating from crop production and animal husbandry has been linked to eutrophication of lakes, rivers and coastal waters (Sharpley and Rekolainen 1997, Ekholm et al. 2005). Some 50\% of the phosphorus loads into the Baltic Sea originate from diffuse sources, and agriculture is responsible for $80 \%$ of the total diffuse nutrient loading (HELCOM 2010).

Controlling phosphorus loading from agriculture is challenging for a variety of reasons. Soil phosphorus, which is a key determinant for both crop yield and agricultural phosphorus loading, accumulates over time. ${ }^{1}$ Through the soil phosphorus level, past phosphorus surpluses (the difference between fertilizer applied to soil and crop uptake) influence current phosphorus loads and abatement opportunities. If soil is very rich in phosphorus, reducing phosphorus loads through depletion of soil phosphorus reserves may take decades. In terms of agri-environmental policies to steer farm management practices, the non-point character of agricultural loading poses a challenge. The emission processes are complex, the loading sources are diffuse, and enforcement is costly. Realistically, water protection policies have to be based on factors that are relatively easily observed (see e.g. Griffin and Bromley 1982, Shortle and Dunn 1986, Horan and Ribaudo 1999). A further challenge is that phosphorus is transported from agricultural land to surface waters in two distinct forms with different biochemical characteristics: particulate phosphorus (PP) and dissolved reactive phosphorus (DRP). The division of phosphorus loading into PP and DRP influences efficient control measures. The main determinant of PP loss is erosion. Usually, only a part of PP loss is transformed into an algal-available form in the receiving water bodies. DRP loss on the other hand is determined mainly by soil phosphorus reserves (Pote et al. 1996, Schroeder et al. 2004). DRP loss is readily in algalavailable form (Ekholm and Krogerus 2003). In terms of erosion and PP loss, vegetative filter strips have proven an effective protection measure. However, results on their effect on DRP loss are ambiguous: filter strips have been found to decrease DRP loss (Schmitt et al. 1999, Lee et al. 2000), increase DRP loss (Uusi-Kämppä and Kilpinen 2000), or both, depending on the experiment (Dillaha et al. 1989). Changing to no-till technology in turn reduces PP loss but may increase DRP loss relative to conventional tillage (Puustinen et al. 2005, Uusitalo et al. 2007a).

\footnotetext{
${ }^{1}$ The characteristics of phosphorus accumulation vary with soil type. Finnish young glacial clay soils are high in aluminum and iron oxides, which make tight bonds with phosphate. In our framework, such characteristic enter the empirical specification of phosphorus transition function (equation 9). Other soil types would require adjusting the empirical specification for phosphorus transition. With appropriate soil phosphorus transition functions the framework developed here can be used to analyze gypsum amendment for other soil types as well.
} 
Recent results from laboratory, field, and catchment scale experiments suggest that applying gypsum $\left(\mathrm{CaSO}_{4}\right)$ on field surface provides a novel, effective means to reduce both dissolved and particulate phosphorus loads (Ekholm et al. 2012, Uusitalo et al. 2012). Applying gypsum increases the ionic strength of soil solution which in turn causes the smallest soil particles - those most susceptible for erosion - to bond together. Larger aggregates are less likely to be carried from fields to receiving waters by both surface runoff and drainage flow. The changes in the chemical characteristics of soil solution also reduce dissolved phosphorus loads. Gypsum is spread on the soil after harvest, while soil is still unfrozen; the machinery is the same as that used for spreading lime. It is not necessary to apply gypsum every year. Laboratory tests by Uusitalo et al. (2012) show that the concentration of sulphate ions is still high after three years of gypsum application. Catchment scale results by Ekholm et al. (2012) also indicate that reductions in phosphorus loads last for at least three years. Gypsum amendment was shown to markedly reduce phosphorus loads from crop production: on average, PP loss was cut back by 57 percent and DRP loss by about 29 percent (Ekholm et al. 2012). In terms of agricultural policy and regulation, gypsum amendment has the advantage that it is very straightforward to observe and thus monitor.

The purpose of this study is to complement the findings from the catchment scale, field and laboratory experiments by examining the economic feasibility of gypsum application as a water protection measure, from the perspective of the society on the whole. Gypsum is a by-product of fertilizer production. In Finland, abundant reserves of gypsum have accumulated in fertilizer manufacturing. However, its transport from production site to farms is relatively costly, and also the costs of application need to be taken into consideration. In addition to its biophysical effects, its impact on farm profits and interaction with another key phosphorus load reduction measure - the adjustment of fertilizer application and, gradually, soil phosphorus levels to crop need - should be accounted for when assessing economic feasibility. To this end, the present study develops a model of agricultural phosphorus management and gypsum amendment. It also examines how gypsum application interacts with another key phosphorus mitigation measure, vegetative filter strips, in an optimal policy combination.

Accumulated soil phosphorus and soil loss through erosion are the key determinants of phosphorus loading from agricultural land into adjacent waterways. The means to mitigate phosphorus loads currently in use typically focus on either particulate or dissolved phosphorus. For a given soil structure, soil type and rainfall, dissolved phosphorus loads are determined by the level of soil phosphorus. Hence, these loads can be mitigated by depleting soil phosphorus levels; the process may, however, come at the expense of crop yields and farm income and take decades if initial soil phosphorus levels are high. The most common means to mitigate erosion currently in use in Finland are constructing vegetative filter strips on field edges bordering waterways, and using soil conserving tillage technologies such as no till.

Degradation of water ecosystems results in economic damage both directly, and through lost value of fisheries and recreational activities. Economic valuation studies have attributed notable monetary damage to eutrophication of waters (see e.g. Söderqvist and Scharin 2000, Markovska and Zylicz 1999, Kosenius 2010, Vesterinen et al. 2010). Significant policy initiatives aim at protecting surface waters - for example, the European Union's Water Framework Directive, and Finland's National Water Protection Guidelines - and a key measure is reducing agricultural loads. Designing economically sound environmental policies for controlling agricultural nutrient loads calls for combining knowledge of economics of crop production, determinants of nutrient losses, and the associated environmental damage. In the case of agricultural phosphorus losses, a fundamental cause of loading is inefficiency in fertilizer use. When phosphorus fertilization exceeds the removal of phosphorus by the crop, most of the surplus phosphorus will remain in the soil and add to the phosphorus reserve (see e.g. Hooda et al. 2001). Soil phosphorus reserve in turn has a dual role in accelerating both crop growth and phosphorus losses. Efficient policies to control agricultural phosphorus loading should weigh the trade-off between profits from production and the environmental damage from phosphorus loading over time. As the agricultural profits and phosphorus losses both depend on the soil phosphorus level, producing policy guidelines that are sound in the long-term requires considering the development of soil phosphorus in conjunction with abatement measures. Thus, dynamic analysis incorporating both production and abatement decisions is warranted.

The dynamically optimal use of phosphorus, in the economic sense, has been analyzed previously for example by Schnitkey and Miranda (1993), Goetz and Zilberman (2000), Goetz and Keusch (2005), and Iho and Laukkanen (2012). These studies all take into account the dynamic aspects of soil phosphorus and its effect on yields and environmental damage. The present paper builds upon the framework in Iho and Laukkanen (2012). Theirs is the first economic study to distinctly model particulate and dissolved phosphorus loads, to take into account the dynamics of the plant-available soil phosphorus reserves and their links to dissolved phosphorus losses, and to analyze the optimal accumulation of soil phosphorus over time in this context. The framework of the present study incorpo- 
rates a new type of choice variable into the model in lho and Laukkanen (2012): It considers gypsum amendment as a means to abate phosphorus losses, together with the long-term development of soil phosphorus reserves and the matching of fertilizer application to crop need. The model developed allows studying how initial soil phosphorus levels and differences in erosion susceptibility affect the economic feasibility of gypsum amendment as a phosphorus load reduction measure.

\section{A dynamic model of farm profits, phosphorus losses, and gypsum amendment}

We consider a field parcel bordering a waterway. For simplicity, we assume that the parcel is square in shape and measures one hectare. A single grain crop is produced using phosphorus fertilizer as a variable input. The fertilizer applied to the land but not utilized by the crop increases soil phosphorus reserves; accumulated soil phosphorus and soil loss through erosion in turn cause phosphorus loss from the field to the adjacent waterway. Phosphorus loss results in environmental damage, suffered by the society on the whole. Consequently, abatement of phosphorus losses becomes part of the optimal phosphorus management problem. In our base scenario we consider treating field surface with gypsum as an explicit abatement measure, but we also study adjusting phosphorus fertilizer application annually based on the current soil phosphorus level. Due to the dual role of phosphorus in accelerating both crop growth and phosphorus loss, the profitability of gypsum amendment from the society's point of view will depend on the field's soil phosphorus level and is therefore linked to fertilizer application. Thus, simultaneously accounting for annual fertilizer application and its impact on soil phosphorus is warranted when analyzing the economics of gypsum amendment. Furthermore, because phosphorus accumulates in soil over time, the economic efficiency of abatement measures should be examined in a dynamic optimization framework.

Finnish field experiments indicate that gypsum does not affect crop yield in the short run (Kari Ylivainio, MTT Agrifood Research Finland, personal communication). The possible indirect effects on yield through changes in soil structure are not known at the time. We abstract away from such effects and assume that gypsum amendment has no impact on yield. Furthermore, rainfall simulations documented in Uusitalo et al. (2012) indicate that gypsum amendment does not affect the transport of the plant-available forms of nitrogen $\left(\mathrm{NO}_{3}-\mathrm{N}_{\text {and }} \mathrm{NH}_{4}-\mathrm{N}\right)$ which directly contribute to eutrophication, but does reduce the concentration of organic nitrogen in percolation water. While reduced transport of organic nitrogen would improve surface water quality in the long run, the effect cannot be quantified on basis of currently available empirical data. Therefore, we also abstract away from the effects of gypsum amendment on eutrophying nitrogen transports. Finally, as long as gypsum amendment does not affect yield or transport of plant-available nitrogen, it will not affect the economically optimal use of nitrogen fertilizer. Consequently, our optimization model and analysis focus on phosphorus.

Laboratory experiments have indicated that there is a threshold value for the amount of gypsum that has to be applied to obtain a response in terms of reduced phosphorus losses. As runoff water transports part of the applied gypsum away from field surface, it is also plausible that there is a level of gypsum application beyond which additional gypsum provides no additional response. Based on the preliminary findings from laboratory experiments, the only available catchment-scale study of the effect of gypsum on phosphorus losses in Finnish conditions (Ekholm et al. 2012) considered just one level of gypsum application, 4.1 tons per hectare. The level was chosen to correspond to the most effective soil gypsum content in Finnish laboratory experiments. Rainfall simulations reported in Uusitalo et al. (2012) considered two levels of gypsum application, 3 and 6 tons per hectare, but the differences in the effects on phosphorus losses were small.

As the economic feasibility of gypsum amendment is an empirical question, we construct our economic model to correspond to the current empirical knowledge on gypsum amendment in Finland. We proceed from the simplification that the proportional reductions in DRP and PP loads provided by gypsum amendment are constant, and that a given amount of gypsum (4.1 tons per hectare in our application) has to be applied to obtain this effect. The decision problem then simplifies to determining the share of field surface to be treated with gypsum, at the given tons per hectare rate. In reality, it may be possible to apply a smaller quantity, down to some threshold, and obtain a smaller effect; or apply a larger quantity, up to some threshold, and obtain a larger effect. Thus, our model provides an approximation that accommodates the current empirical knowledge on the effect of gypsum amendment in Finland. Once experimental results become available on the impact of different gypsum amendment rates on DRP and PP loads, the model should be modified so that the reductions in DRP and PP loads are functions of the amount of gypsum applied per hectare. 
As gypsum amendment reduces DRP and PP loads, a plausible assumption would be that it also affects the development of soil phosphorus reserves over time. However, while important in terms of eutrophication, the amounts of DRP and PP retained by gypsum are small relative to the amounts taken up by the crop. The studies of Ekholm et al. (2012) and Uusitalo et al. (2012) found that the soil phosphorus reserve, measured by STP, remained unchanged during the three years after gypsum amendment analyzed in the studies. In line with this finding, we proceed from the assumption that gypsum amendment does not affect the transition on soil phosphorus from one period to the next.

Formally, grain production and the associated phosphorus loss and abatement measures are modeled as follows. The per hectare production function is $Y\left(s_{t}, x_{t}\right)$, where $s_{t}$ denotes the current soil phosphorus level, measured as soil test $\mathrm{P}$ (STP), and $x_{t}$ phosphorus fertilizer applied in the current year. The STP level in period $t+1$ is determined by previous period's STP level and fertilization according to the state transition function $s_{t+1}=\Gamma\left(s_{t}, x_{t}\right)$. The product and input prices are denoted by $p$ and $w$. Operational costs per hectare are denoted by $r$ and include costs such as seeds, labor and the rental or annualized cost of machinery. Field and laboratory experiments suggest that gypsum application in three year intervals is sufficient to capture the full phosphorus abatement potential of gypsum amendment (Ekholm et al. 2012, Uusitalo et al. 2012). We proceed from the simplifying assumption that the decision on gypsum amendment is an annual one, which we consider a reasonable approximation in that the three year period is still fairly short and farm operating environment, in particular the STP level, do not change much in such a time frame. ${ }^{2}$ We let $a_{t}$ denote the share of the field parcel treated with gypsum in the current year. The total phosphorus load per hectare includes the DRP load $L_{D R P}\left(s_{t}\right)$ and the bioavailable PP load $L_{p P}$. As the erosion is determined mainly by field slope, we proceed from the assumption that $L_{p P}$ is constant relative to the control and state variables in our model. ${ }^{3}$ We let $T_{D R P}$ and $T_{P P}$ denote the constant proportional reductions in these loads provided by gypsum amendment. The total phosphorus load from field to waterway is given by $\left(1-a_{t} T_{D R P}\right) L_{D R P}\left(s_{t}\right)+\left(1-a_{t} T_{P P}\right) L_{P P}$. The costs of gypsum treatment are given by $g a_{t}$ and include the costs of gypsum and the machinery and labor required for its application. The available empirical data only allow us to consider a linear damage function. The per-period monetary damage resulting from phosphorus loading is given by $m\left[\left(1-a_{t} T_{D R P}\right) L_{D R P}\left(s_{t}\right)+\left(1-a_{t} T_{P P}\right) L_{P P}\right]$, where $m$ is the marginal damage from phosphorus loading or, equivalently, the marginal benefit from reducing phosphorus loading.

Summing up, the per-period, per-hectare social net return from crop production is

$$
\Pi\left(s_{t}, x_{t}, a_{t}\right)=\left[p Y\left(s_{t}, x_{t}\right)-w x_{t}-r\right]-g a_{t}-m\left[\left(1-a_{t} T_{D R P}\right) L_{D R P}\left(s_{t}\right)+\left(1-a_{t} T_{P P}\right) L_{P P}\right]
$$

The social net return incorporates the environmental damage pertaining to agricultural phosphorus loss. The private profit from farming is given by $\Psi\left(s_{t}, x_{t}, a_{t}\right)=\left[p Y\left(s_{t}, x_{t}\right)-w x_{t}-r\right]-g a_{t}$.

\section{Optimal gypsum amendment and fertilizer application rates}

We are concerned with long term socially optimal gypsum amendment and fertilizer application decisions. Other production inputs are assumed to be fixed. From the society's point of view the decision problem is to maximize the present discounted value of net rewards from production, which equal farm profits minus the monetary value of environmental damage caused by phosphorus loading into waterways. Formally, the discrete-time, continuousstate decision problem is given by

$$
\max _{\substack{0 \leq a_{t} \leq 1 \\ 0 \leq x_{t}}} \sum_{t=0}^{\infty} \beta^{t}\left\{p Y\left(s_{t}, x_{t}\right)-w x_{t}-r-g a_{t}-m\left[\left(1-a_{t} T_{D R P}\right) L_{D R P}\left(s_{t}\right)+\left(1-a_{t} T_{P P}\right) L_{P P}\right]\right\}
$$

subject to $s_{t+1}=\Gamma\left(s_{t}, x_{t}\right), s_{0}=S_{0}, x_{t} \geq 0$, and $0 \leq a_{t} \leq 1$. Parameter $S_{0}$ denotes the initial STP level, and $\beta$ is the discount factor corresponding to the social discount rate $\delta$, with $\beta=\frac{1}{1+\delta}$.

\footnotetext{
${ }^{2}$ The assumption is made to keep the dynamic analysis tractable. Adopting a three-year decision interval would not change the key results, but would significantly complicate the numerical analysis. The cost of gypsum application is also annualized: the costs of gypsum treatment suggested by field experiments are divided by three to approximate annual treatment costs.

${ }^{3}$ The bioavailability of PP and hence the magnitude of the bioavailable PP load may in principle be affected by soil phosphorus. Iho and Laukkanen (2012) model the bioavailability of PP as a function of STP, with minor effects on results under conditions representative for crop farming in Finland. As the focus here is on gypsum amendment, for the ease of exposition we abstract away from the small changes in the PP load related to soil phosphorus.
} 
The STP level changes only slowly over time, steered by phosphorus surplus (the difference between fertilizer applied to soil and crop uptake). Through the STP level, the past has a direct influence on current opportunities, and current decisions affect future outcomes. Dynamic programming provides a means to study intertemporally optimal farming decisions that account for the links between the past, the current, and the future. We let $V\left(s_{t}\right)$ denote the maximum attainable sum of current and future net benefits given a current STP level of $s_{t}$. Bellman's (1957) principle of optimality implies that the optimal policy must satisfy the functional equation

$$
V\left(s_{t}\right)=\max _{\substack{0 \leq a_{t} \leq 1 \\ 0 \leq x_{t}}}\left\{\Pi\left(s_{t}, x_{t}, a_{t}\right)+\beta V\left(s_{t+1}\right)\right\}
$$

Acknowledging the constraints $0 \leq a_{t} \leq 1$ and $0 \leq x_{t}$, the first order conditions to the problem are

$$
\begin{aligned}
& \Pi_{a}\left(s_{t}, a_{t}, x_{t}\right)+\beta \lambda\left(s_{t+1}\right) \Gamma_{a}\left(s_{t}, x_{t}\right)=\mu_{a t} \\
& \Pi_{x}\left(s_{t}, a_{t}, x_{t}\right)+\beta \lambda\left(s_{t+1}\right) \Gamma_{x}\left(s_{t}, x_{t}\right)=\mu_{x t},
\end{aligned}
$$

where $\Pi_{a}, \Gamma_{a}, \Pi_{x}$ and $\Gamma_{x}$ denote partial derivatives with respect to $a$ and $x, \lambda\left(s_{t+1}\right) \equiv V^{\prime}\left(s_{t+1}\right)$ is the shadow value of the STP reserve in period $t+1$ and $\mu_{a t}$ and $\mu_{x t}$ measure the current and future reward from a marginal increase in the choice variables $a$ and $x$. In addition to (4), $a_{t}, x_{t}, \mu_{a t}$, and $\mu_{x t}$ have to satisfy the complementarity conditions

$$
\begin{aligned}
& a_{t}>0 \Rightarrow \mu_{a t} \geq 0 ; \quad a_{t}<1 \Rightarrow \mu_{a t} \leq 0 ; \\
& x_{t}>0 \Rightarrow \mu_{x t}=0 ;
\end{aligned}
$$

Consider first the optimal share of the field parcel to be treated with gypsum, $a_{t}$. As gypsum treatment does not affect the development of STP, $\Gamma_{a}\left(s_{t}, x_{t}\right)=0$, and as the per hectare gypsum amendment cost and the treatment effect are constant, $\Pi\left(s_{t}, x_{t}, a_{t}\right)$ is linear in $a_{t}$. Its derivative thus does not depend on $a_{t}$, and the marginal impact of $a_{t}$ on $\Pi\left(s_{t}, x_{t}, a_{t}\right)$ will be either positive, negative, or zero for all $a_{t}$ : either (i) $\Pi_{a}=-g+m\left[T_{D R P} L_{D R P}\left(s_{t}\right)+T_{P P} L_{P P}\right]>0$, (ii) $\Pi_{a}=-g+m\left[T_{D R P} L_{D R P}\left(s_{t}\right)+T_{P P} L_{P P}\right]<0$, or (iii) $\Pi_{a}=-g+m\left[T_{D R P} L_{D R P}\left(s_{t}\right)+T_{P P} L_{P P}\right]=0$ for all $a_{t}$. As $\Gamma_{a}\left(s_{t}, x_{t}\right)=0$, equation (4) then implies that the optimal choice of $a_{t}$ will in general be a boundary one. In case (i), the marginal reduction in damage from phosphorus loading exceeds the marginal cost of gypsum treatment for all $a_{t}$, and it is optimal to treat the entire parcel with gypsum ( $a_{t}=1$ and $\left.\mu_{a t} \geq 0\right)$; in case (ii), the marginal reduction in damage falls below the marginal cost of treatment for all $a_{t}$, and it is optimal not to apply gypsum at all ( $a_{t}=0$ and $\left.\mu_{a t} \leq 0\right)$. In case (iii), the optimal choice of $a_{t}$ is arbitrary (conditions 4 and 5 will be satisfied for any value of $a_{t}$ ). The marginal reduction in damage depends on $s_{t}$, and the decision whether to apply gypsum or not will hence change as the STP level changes.

Consider next the optimal fertilization rate, $x_{t}$. The optimal choice of $x_{t}$, for a given STP level $s_{t}$, is determined by the first-order condition

$$
\begin{aligned}
& {\left[p Y_{x}\left(s_{t}, x_{t}\right)-w\right]+\beta \lambda\left(s_{t+1}\right) \Gamma_{x}\left(s_{t}, x_{t}\right)=\mu_{x t} ;} \\
& x_{t}>0 \Rightarrow \mu_{x t}=0 .
\end{aligned}
$$

Again, $Y_{x}$ and $\Gamma_{x}$ denote partial derivatives with respect to $x_{t}$. Fertilization is not constrained from above. Therefore, an interior solution implies that the shadow value of the non-negativity constraint, $\mu_{x t}$, is zero. Thus, for an interior solution the first-order condition (4) states that fertilizer should be applied to the point where the sum of its marginal impact on profits in the current period and the marginal impact on the discounted value of the phosphorus reserve in the next period equals zero. A binding constraint $\left(x_{t}=0\right)$ implies a non-positive shadow value for the constraint. That is, a marginal increase on the constraint would have a non-positive effect on the current and future reward.

The envelope theorem applied to the same problem implies

$$
\lambda\left(s_{t}\right)=\left[p Y_{s}\left(s_{t}, x_{t}\right)\right]-m\left(1-a_{t} T_{D R P}\right) L_{D R P, s}\left(s_{t}\right)+\beta \lambda\left(s_{t+1}\right) \Gamma_{s}\left(s_{t}, x_{t}\right)
$$

Here, $Y_{s}, L_{D R P, s}$ and $\Gamma_{s}$ denote partial derivatives with respect to $s_{t}$. Equation (7) indicates that the shadow value of soil phosphorus in the current period equals the sum of its marginal impact on the current period profits, net of the marginal impact on the costs of generated runoff, and the discounted value of the marginal increase in the phosphorus reserve in the following period.

A farmer's private problem is limited to the present discounted value of profits, and the intertemporal optimization problem is identical to that described by equations (2) and (3) with the exclusion of the term $m\left[\left(1-a_{t} T_{D R P}\right) L_{D R P}\left(s_{t}\right)+\left(1-a_{t} T_{P P}\right) L_{P P}\right]$. The solution to the farmer's problem is defined by equations (4) to (7) with the 
terms describing marginal damage from phosphorus loading set equal to zero. The shadow value of STP in (7), $\lambda\left(s_{t}\right)$, then only accounts for the marginal impact of STP on profits from production and on the STP in the following period. The marginal impact of gypsum amendment on the farmer's payoff functional will equal - $g$, a negative quantity. Hence, a private farmer will not apply gypsum without policy intervention. Furthermore, assuming that crop yield is concave in its arguments, the farmer's privately optimal fertilizer application rate will exceed the socially optimal rate.

As shown above, whether gypsum amendment will be economically feasible will depend on the STP level. The optimal path of STP level over time in turn has to accommodate the trade-off between the roles that STP plays in both crop growth and environmental degradation. The characteristics of agricultural phosphorus management raise interesting empirical questions regarding the potential of gypsum amendment as a new abatement measure: What are the break-even levels of STP that make gypsum amendment economically feasible, and how are these levels influenced by the key ecological characteristics of the site, such as susceptibility to erosion? What kind of policy interventions are then needed to provide farmers with incentives to adopt gypsum amendment as a water protection measure? What is the optimal mix of abatement through gypsum application, depletion of soil phosphorus reserves, and erosion control? To study these questions in a realistic setting, we next construct a detailed empirical model of crop production and phosphorus loading with barley as the sample crop. We then empirically evaluate the economic performance of gypsum amendment, in conjunction with long-term optimal phosphorus fertilization.

\section{Empirical model components}

The empirical model is parameterized for production conditions in southern Finland, Uusimaa and Varsinais-Suomi provinces bordering the Baltic Sea. Our description of the empirical model components starts out with the impact of soil phosphorus and phosphorus fertilization on yield and the accumulation of soil phosphorus. We then depict the links from soil phosphorus and erosion to phosphorus loading, and describe the impact of gypsum amendment as well as its costs. The empirical model is parameterized for sandy clay soils in southern Finland and for barley as a sample crop. Throughout the empirical illustration, soil phosphorus level is expressed as agronomic soil test phosphorus (STP). The model components describing crop production, accumulation of soil phosphorus and phosphorus loading have been compiled from previously published research in soil and environmental sciences. We therefore describe these model components only briefly, referring the reader to the original sources for a more detailed discussion.

\section{Crop production function}

The yield response to phosphorus consists of the impacts of the fertilizer applied and the phosphorus accumulated in the soil. Following Myyrä et al. (2007), we specify the phosphorus response function for barley as

$$
Y(s, x)=\alpha_{1}^{Y}\left(1-\alpha_{2}^{Y} e^{-\alpha_{3}^{\gamma} s}\right)+\left(\alpha_{4}^{Y}-\alpha_{5}^{Y} s\right) \sqrt{x}+\frac{\left(\alpha_{6}^{Y}-\alpha_{7}^{Y} x\right) x}{s}+\alpha_{8}^{Y} .
$$

From Myyrä et al. (2007), the parameter values for barley production in southern Finland are $\alpha_{2}^{\gamma}=0.74, \alpha_{3}^{\gamma}=0.37$, $\alpha_{4}^{\gamma}=21.7, \alpha_{5}^{\gamma}=0.414, \alpha_{6}^{\gamma}=17.01, \alpha_{7}^{\gamma}=0.1817$ and $\alpha_{8}^{\gamma}=5.856$. The maximum yield parameter $\alpha_{1}^{\gamma}=4319$ was calibrated to correspond to the 75th percentile of observed barley yields for a sample of 249 farms in Southern Finland over the years 1998-2005 (Agrifood Research Finland profitability bookkeeping data for support region A).

\section{Development of soil phosphorus}

Ekholm et al. (2005) model the relationship between the development of STP and the phosphorus surplus, that is, the fertilizer applied to the land but not utilized by the crop. The phosphorus surplus is defined by $P_{b a l}(s, x)=x-\Lambda(s) Y(s, x)$, where $\Lambda(s)$ is the phosphorus concentration of the crop yield. Saarela et al. (1995) provide information that allows specification of the phosphorus concentration of crop yield as a logarithmic function of the STP. Following Ekholm et al. (2005), the STP level in the following year is then specified as follows:

$$
\Gamma(s, x)=\alpha_{1}^{\Gamma} s+\left(\alpha_{2}^{\Gamma}+\alpha_{3}^{\Gamma} s\right)\left[x-\left(\alpha_{4}^{\Gamma} \ln (s)+\alpha_{5}^{\Gamma}\right) Y(s, x)\right]
$$

where the term $\left[x-\left(\alpha_{4}^{\Gamma} \ln (s)+\alpha_{5}^{\Gamma}\right) Y(s, x)\right]$ is the phosphorus surplus and the term $\alpha_{4}^{\Gamma} \ln (s)+\alpha_{5}^{\Gamma}$ defines the phosphorus concentration of the crop yield. The parameter estimates $\alpha_{1}^{\Gamma}=0.9816, \alpha_{2}^{\Gamma}=0.0032$ and $\alpha_{3}^{\Gamma}=0.00084$ 
were obtained directly from Ekholm et al. (2005). ${ }^{4}$ The parameter estimates $\alpha_{4}^{\Gamma}=0.000186$ and $\alpha_{5}^{\Gamma}=0.003$ were obtained from data in Saarela et al. (1995) through ordinary least squares estimation. ${ }^{5}$

\section{Phosphorus loads and abatement through gypsum amendment}

In our model, total phosphorus load per hectare includes the DRP load and the bioavailable fraction of the PP load. Following Uusitalo and Jansson (2002), the annual DRP load ( $\mathrm{kg} \mathrm{ha}^{-1}$ ) from crop production is specified as a linear function of the STP level:

$$
L_{D R P}(s)=\alpha_{1}^{D R P} s-\alpha_{2}^{D R P}
$$

The PP runoff potential of the sandy clay soils in southern Finland varies mainly according to field slope (Puustinen et al. 1994). While the topography of the land in production is taken as given here, we construct the PP loss component in a way that facilitates parameterizing and evaluating the model for different field slopes. In line with the universal soil loss equation (Wischmeier and Smith 1978), the annual PP loss (kg ha-1) is specified as a quadratic function of field slope:

$$
L_{P P}(\gamma)=b\left(\alpha_{1}^{P P} \gamma^{2}+\alpha_{2}^{P P} \gamma+\alpha_{3}^{P P}\right)
$$

Only a proportion of PP contributes to the bioavailable phosphorus load; the multiplier $b$ denotes this proportion.Gypsum reduces the loads of DRP and PP by proportions denoted by $T_{D R P}$ and $T_{P P}$. Recall also that $a_{t}$ indicates the share of field surface treated with gypsum. From equations (10)-(11), the total bioavailable phosphorus load is given by

$$
L_{P}(s, a)=\left(1-a T_{D R P}\right)\left(\alpha_{1}^{D R P} s-\alpha_{2}^{D R P}\right)+b\left(1-a T_{P P}\right)\left(\alpha_{1}^{P P} \gamma^{2}+\alpha_{2}^{P P} \gamma+\alpha_{3}^{P P}\right)
$$

The parameter estimates $\alpha_{1}^{D R P}=0.0567$ and $\alpha_{2}^{D R P}=0.0405$ for equation (12) were obtained by multiplying the estimates of DP concentration in $\mathrm{mg} \mathrm{l}^{-1}$ in Uusitalo and Jansson (2002) by an estimated runoff volume of $2700000 \mathrm{I} \mathrm{ha-1}$ (Ekholm et al. 2005) and converting the units to kg $\mathrm{ha}^{-1}$. The data in Uusitalo et al. (2007a) produce parameter estimates of $\alpha_{1}^{P P}=0.035, \alpha_{2}^{P P}=0.12$ and $\alpha_{3}^{P P}=0.37$ for equation (12). The bioavailability coefficient $b=0.16$ was obtained from Ekholm et al. (2005). Finally, results on the impact of gypsum amendment on phosphorus loads in Ekholm et al. (2012) yield parameter values $T_{D R P}=0.29$ and $T_{P P}=0.57$.

\section{Prices and costs}

All prices and costs have been deflated to year 2005. Product price $p$ was computed as a weighted average of feed and malting barley prices in the period 2002-2009. The data for prices and areas in feed and malting barley production were obtained from the Information Center of the Ministry of Agriculture. The phosphorus fertilizer price $w$ was computed from a price series for 2002-2009, obtained from Yara Finland. The resulting product and fertilizer prices are $0.11 € \mathrm{~kg}^{-1}$ and $1.56 € \mathrm{~kg}^{-1}$, respectively. The operational costs, $r$, include seeds, nitrogen and potassium fertilization, herbicides and pesticides, labor, and operational costs of machinery, all set at the expected per ha use for barley production in southern Finland. The costs were compiled from the Pro Agria agricultural advisory center's Tuottopehtori on-line farm management tool and equal $354 €$ ha $^{-1}$. Finally, the discount rate was set at $5 \%$.

The unit costs of gypsum application, $g$, consist of the product price, freight, and application. It is estimated that applying 4.1 tons of gypsum per hectare once in every three years suffices to achieve the full phosphorus load reduction effect (Ekholm et al. 2012). The costs components are as follows: product price $18.15 €$ ton $^{-1}$, which consist of the costs of cleaning the gypsum produced as a by-product of phosphorus fertilizers such that it can safely be applied to fields; average freight from the production site in Siilinjärvi to southern Finland (Uusimaa province) $29.7 €$ ton $^{-1} 6$; and application $5.5 €$ ton $^{-1}$ (personal communication, Reetta Palva, Finnish Work Efficiency Institute). Under the assumption of a 4.1 tons $\mathrm{ha}^{-1}$ application rate once in every three years, the annualized costs of gypsum amendment are $73 € \mathrm{ha}^{-1}$.

\footnotetext{
${ }^{4}$ The transition function presented by Ekholm et al. (2005) depicts changes in STP with a time step of 10-15 years with a constant phosphorus surplus over the period. Using a one-year time step predicts STP values in the long term that differ slightly from those predicted by the Ekholm et al. (2005) equation. For initial STP levels ranging from 2 to $40 \mathrm{mg} \mathrm{I-1}$ and P surpluses from -5 to $25 \mathrm{~kg}$ ha- $1 \mathrm{y}-1$, the differences in STP values for year 30 predicted by equation (9) with a constant phosphorus surplus and one- and ten-year time steps were 0 to $8 \%$.

${ }^{5}$ The phosphorus concentration data in Saarela et al. (1995) were measured from dry matter. Their data were made commensurate with storage weight yield prior to the estimation.

${ }^{6}$ The product price and freight costs are adopted from an auction field trial conducted in Nurmijärvi in 2010.
} 


\section{Damage from phosphorus loading}

The damage from phosphorus loading relates to degraded water quality in the body of water receiving the phosphorus loads. The empirical model is parameterized for production conditions in southern Finland, Uusimaa and Varsinais-Suomi provinces bordering the Baltic Sea. Rivers from this area transport phosphorus into the Gulf of Finland and the Archipelago Sea. In coastal regions such as our study region, with a high proportion of agricultural land and a low lake percentage, retention in river channels is minor and most of the nutrient loading from agricultural areas enters coastal waters (Rekolainen et al. 1995). ${ }^{7}$ The retention rate for phosphorus in the study area was determined from an empirical regression model that predicts nutrient fluxes with field and lake percentages as explanatory factors (see Rankinen et al. 2010). ${ }^{8}$ The resulting phosphorus retention rate is $15 \%$. Thus, approximately $85 \%$ of the phosphorus load from the study area finds its way into the Gulf of Finland or the Archipelago Sea.

Determining the economic feasibility of gypsum amendment requires expressing the benefits of reduced phosphorus loading in monetary terms. Improved water quality is a non-market good - there are no market transactions that could be used to determine its value. Instead, the value has to be determined using non-market valuation methods developed in economics. In the case of the Gulf of Finland and the Archipelago Sea, measuring the nonmarket benefits of reduced phosphorus loading is complicated by the fact that surface water quality degradation is governed by the joint presence of nitrogen and phosphorus (see e.g. Tamminen and Andersen 2007). Consequently, water quality improvements are attributable to the combined effect of changes in nitrogen and phosphorus loads entering the water ecosystem.

Kosenius (2010) has estimated the benefits of improved water quality in the Gulf of Finland and the Archipelago Sea. Her valuation study built on water quality attributes forecast by Baltic Sea ecosystem models for combined phosphorus and nitrogen load reduction scenarios (reported in Pitkänen et al. 2007). As water quality improvements relate to the combined effect of phosphorus and nitrogen load reductions, a composite measure of nitrogen and phosphorus loads is needed for connecting Kosenius' willingness to pay results to reduced nutrient loading. We use the sum of phosphorus and nitrogen as such a combined measure. That is, we assume that environmental benefits arise from reductions in a per year composite nutrient load $L_{N P, t}$, defined as

$$
L_{N P, t}=L_{P, t}+L_{N, t}
$$

where $L_{p, t}$ is the per year phosphorus load and $L_{N, t}$ the per year nitrogen load. This index is introduced to provide an overall measurement of nutrient load reductions, and we acknowledge that there is ultimately no way of measuring the imperfections of the index against reality.

The scenario in Kosenius (2010) relevant to this study reduced Finland's loads to the Gulf of Finland and the Finnish Archipelago Sea, for phosphorus by 525 tons per year and for nitrogen by 7986 tons per year relative to the 1997-2002 levels. ${ }^{9}$ The study accounted for time lags in obtaining the environmental benefits of reduced nutrient loading by considering a 20 year time frame: Respondents were told that the load reductions would be in place for 20 years, after which water quality attributes would have improved in accordance with the long-term ecosystem model forecasts reported in Pitkänen et al. (2007). The Finnish population's per year willingness to pay for the load reductions provides a measure of the benefits associated with reducing nutrient loads. The estimates obtained by Kosenius (2010) range from 652 million euros per year for a multinomial logit model to 945 million euros per year for a random parameters logit model. ${ }^{10}$

We computed a constant marginal benefit of composite nutrient load reduction by dividing the national benefit, 652 or 945 million euros, by the nutrient load reduction underlying the valuation scenario, measured as a composite nutrient load reduction of 525 tons of phosphorus plus 7986 tons of nitrogen per year. As phosphorus and nitrogen have equal weights in our composite nutrient load measure, the constant marginal benefit of reducing phosphorus loading is equal to that of reducing composite nutrient loading. Finally, the load reduction scenario in

\footnotetext{
${ }^{7}$ Retention refers to the discrepancy between the measured nutrient transport and the estimated total emission of nutrients due to e.g. biological uptake and sedimentation of nutrients.

${ }^{8}$ We thank Petri Ekholm, Finnish Environment Institute, for assessing the retention rate from the regression model. The lake and field percentages for the study area were obtained from the Corine 2006 Land Cover raster data for Finland.

${ }^{9}$ The other scenarios concerned intensified wastewater treatment in Russia and reductions in Polish loads to the Baltic Proper.

10 Kosenius considered altogether three model specifications: a multinomial logit model, a random parameters logit model, and a latent class model. We do not consider the willingness to pay estimates from the latent class model in our analysis as they were not weighted for population representativeness.
} 
the valuation study concerns total nutrients whereas our phosphorus load functions predict bioavailable phosphorus loads. We adjust the marginal benefit measure to correspond to bioavailable phosphorus by dividing by the average phosphorus bioavailability coefficient 0.43 for loads entering the Baltic Sea (computed from Pitkänen et al. 2007) ${ }^{11}$. Furthermore, due to retention not all but some $85 \%$ of the agricultural phosphorus load enters the sea. To get a measure for the marginal benefit of reducing phosphorus loading from agricultural areas, we multiply the marginal benefit estimate for reducing phosphorus loading reaching the sea by 0.85 .

We obtain two distinct estimates for the constant marginal benefit of reducing agricultural phosphorus loading: $151 € \mathrm{~kg}^{-1}$ when using results from Kosenius' multinomial logit model, and $219 € \mathrm{~kg}^{-1}$ when using results from the random parameters logit model (both in 2005 prices). The $95 \%$ confidence intervals are $139-163 € \mathrm{~kg}^{-1}$ for multinomial logit and $207-232 € \mathrm{~kg}^{-1}$ for random parameters logit. Under the assumption of linear damage function, the marginal damage from agricultural phosphorus loading, denoted by $m$ in our model, equals the marginal benefit of reduced agricultural phosphorus loading. As it is not possible to pin the marginal benefit measure down in an unambiguous way, we analyze the feasibility of gypsum amendment for values of $m$ in the range $139-232 € \mathrm{~kg}^{-1}$.

\section{Solution method}

To determine the optimal phosphorus control policies over time, the dynamic program in (3) was solved numerically using the collocation method. This technique involves writing the value function approximant as a linear combination of $\mathrm{n}$ known basis functions $\phi_{1}, \phi_{2}, \ldots, \phi_{\mathrm{n}}$ whose coefficients $\mathrm{c}_{1}, \mathrm{c}_{2}, \ldots, \mathrm{c}_{\mathrm{n}}$ are determined by the equation

$$
v(s) \approx \sum_{j=1}^{n} c_{j} \phi_{j}(s)
$$

The coefficients $c_{1}, c_{2}, \ldots, c_{n}$ are defined by requiring the value function approximant to satisfy the Bellman equation (3) at a finite set of collocation nodes. The solution was implemented using the CompEcon Toolbox for Matlab. ${ }^{12}$ The solution produces policy functions for $x(s)$ and $a(s)$ that provide a mapping from the current STP level to the optimal fertilization rate and gypsum treatment decision.

\section{Results Economic feasibility of gypsum amendment varies across field slopes, STP levels and
the estimated damage from phosphorus loading}

Whether or not gypsum amendment is an economically feasible phosphorus load mitigation measure is determined by whether the environmental benefits, in terms of phosphorus load reductions evaluated in monetary terms, exceed the costs. The phosphorus load reductions achieved by gypsum amendment in turn depend on the phosphorus load potential of the field, which in the Finnish conditions is determined largely by the field STP level and slope. ${ }^{13}$ Figure 1 displays the results for the feasibility of gypsum amendment for plausible values of marginal damage from phosphorus loading (equal to marginal benefit of phosphorus load reduction) and for comprehensive ranges of field STP levels and slopes. Field STP levels in the study area vary markedly. In Varsinais-Suomi province approximately $25 \%$ of field area has STP values at or below $10 \mathrm{mg} \mathrm{l}^{-1}$, and $25 \%$ of field area STP values at or above $22 \mathrm{mg} \mathrm{l}^{-1}$; in Uusimaa province $25 \%$ of field area has STP values at or below $7 \mathrm{mg} \mathrm{l}^{-1}$, and $25 \%$ of field area STP values at or above $13 \mathrm{mg} \mathrm{l}^{-1}$ (Uusitalo et al. 2007b). ${ }^{14}$ The range from 5 to $26 \mathrm{mg} \mathrm{l}^{-1}$ displayed in Figure 1 suffices to report the thresholds at which gypsum amendment becomes economically feasible for relevant field slopes. The field slope range from 0 to $7 \%$ is comprehensive for Finland and comprises field slopes found in the study area. ${ }^{15}$

\footnotetext{
${ }^{11}$ Notice that the average bioavailability coefficient 0.43 here refers to the average for all phosphorus loads entering the Baltic Sea; this measure is different from the average bioavailability coefficient for PP, which as indicated above is set equal to 0.16 .

12 The Matlab code is available from the authors upon request. The CompEcon Toolbox is a library of Matlab functions, developed to accompany Miranda and Fackler (2002), for numerically solving problems in economics and finance. The library is downloadable at http:// www4.ncsu.edu/ pfackler/compecon/toolbox.html.

${ }^{13}$ For identical soil type and structure, farming practices, rainfall, etc, field slope largely determines the load potential for particulate phosphorus (Wischmeier and Smith 1978, Puustinen et al. 2010).

${ }^{14}$ Uusitalo et al. (2007b) provide results for Uusimaa and for Southwest Finland. As defined in Uusitalo et al. (2007b) Southwest Finland differs from Varsinais-Suomi province in that it includes the island of Ahvenanmaa.

${ }^{15}$ The average slope is $0-1 \%$ for some $57 \%$ of parcels in Finland; $1-3 \%$ for $26 \%$ of parcels; and greater than $7 \%$ for $3 \%$ of parcels (Puustinen et al. 1994).
} 


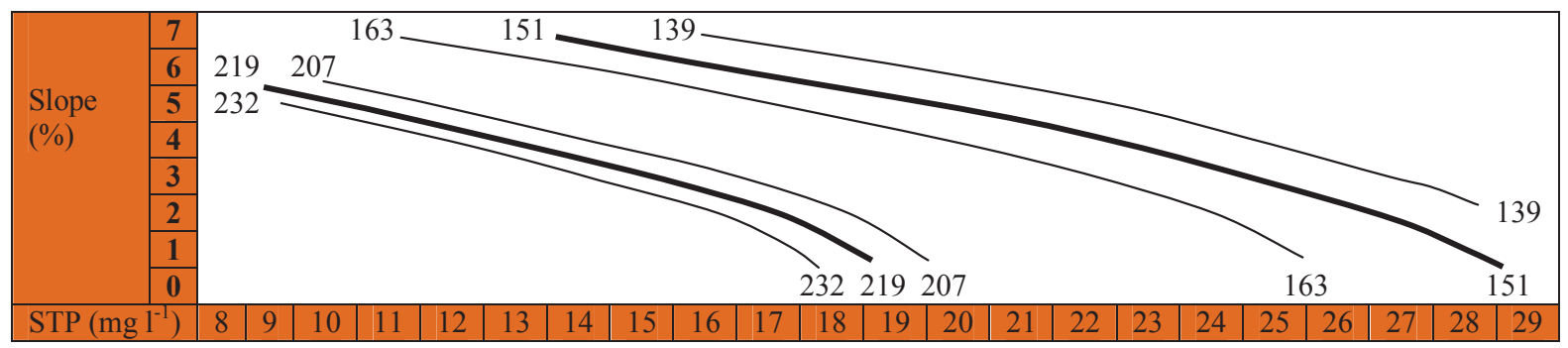

Fig. 1. Economic feasibility of gypsum application for plausible values of marginal damage and various field STP levels and slopes.

Figure 1 depicts threshold STP and slope combinations for six different marginal damage values. Above and to the right of each line in the STP-slope space, gypsum amendment would provide an economically viable abatement option for the marginal damage value labeling the line. The thick lines represent the two marginal damage point estimates, $151 € \mathrm{~kg}^{-1}$ and $219 € \mathrm{~kg}^{-1}$; thin lines correspond to the $95 \%$ confidence intervals. Each line in Figure 1 depicts a combination of field slope and STP level pairs at which gypsum application becomes economically feasible for a given marginal damage parameter. The level of marginal damage is obviously important in determining the economic feasibility of gypsum amendment. Figure 1 demonstrates, for instance, that if the marginal damage is $151 € \mathrm{~kg}^{-1}$, gypsum amendment provides an economically viable abatement option for fields with an STP level exceeding $29 \mathrm{mg} \mathrm{l}^{-1}$, regardless of field slope. Even on a level field with $0 \%$ slope, it would be optimal to apply gypsum if the STP level were $29 \mathrm{mg} \mathrm{l}^{-1}$ or higher. If the slope were 4\%, gypsum amendment would be viable for field parcels with STP $24 \mathrm{mg} \mathrm{l}^{-1}$ or above; and for 7\% slope for parcels with $14 \mathrm{mg} \mathrm{l}^{-1}$ and above. The threshold for the feasibility of gypsum amendment decreases with field slope. Overall, the results in Figure 1 indicate that gypsum amendment as a phosphorus abatement measure is best suited for environmentally sensitive conditions, where either field erosion potential is high due to a steep field slope, or DRP load potential is high due to an elevated STP level, or both.

It should be noted, however, that gypsum amendment does not replace depletion of high phosphorus reserves as a means to reduce phosphorus loading in the long term. The results in Figure 1 only indicate that gypsum amendment should be adopted as an immediate abatement measure where the current STP level is relatively high, while the overall results from the optimization model show that the long-term optimal policy also calls for bringing the STP level down through adjusting fertilization levels.

Figure 2 illustrates the optimal long term policy that also controls the STP level through adjusting the fertilizer application rate. Here, the field slope is set at $2 \%$, which represents the average conditions in Finland. The initial STP level is set at $50 \mathrm{mg} \mathrm{l}^{-1}$, representing soils precariously rich in phosphorus. The marginal damage from phosphorus loading is set at $151 € \mathrm{~kg}^{-1}$, corresponding to the more conservative point estimate derived based on Kosenius' (2010) results. Here, the optimal phosphorus load mitigation policy would call for initially very low fertilizer application rates in conjunction with gypsum amendment. Once the STP level has been brought down $26 \mathrm{mg} \mathrm{l}^{-1}$, gypsum amendment is optimally given up, which is in about 20 years. Depletion of the soil phosphorus level through reduced fertilization continues until the optimal steady state level of $4.9 \mathrm{mg} \mathrm{l}^{-1}$ is reached. The time needed for depleting the soil phosphorus level close to its optimal steady state level is half a century in this case. Gypsum amendment will be used to curtail phosphorus losses over the first twenty years.

\section{The value of adopting gypsum amendment as a phosphorus load reduction measure}

In dynamic programming, the value function $V(s)$ describes the best possible value of the objective, given the STP level s. One way to illustrate the value of gypsum application is to compare the value functions associated with two different sets of choice variables: (1) one in which the decision maker can control phosphorus loading only through adjusting annual phosphorus fertilization levels to crop need and the prevailing STP level, and (2) one in which the decision maker can also choose whether or not to apply gypsum. A value function maps the sum of the discounted net benefits generated by an optimal policy to the current STP level. That is, given that the current STP level is $s$, if optimal policies were followed from the present period to infinity, the value function $V(s)$ would indicate the value of the stream of discounted net benefits achieved from this period onwards. Due to discounting this value is a finite number. 

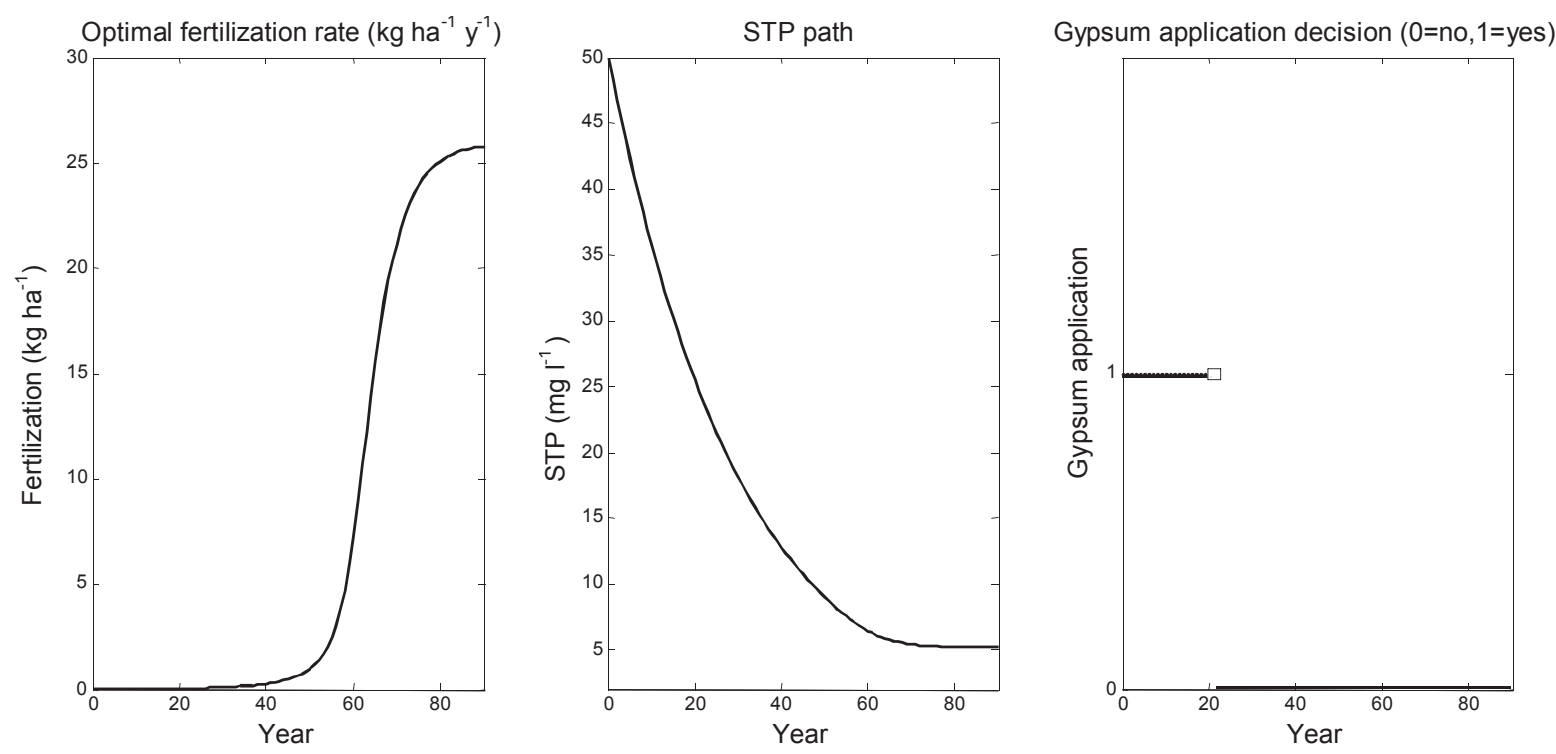

Fig. 2. Gypsum application and soil phosphorus depletion.

Figure 3 presents the two value functions, again for a field with a $2 \%$ slope and with the marginal damage from phosphorus loading set at $151 € \mathrm{~kg}^{-1}$. Figure 1 indicated that for a $2 \%$ slope applying gypsum is optimal whenever the current STP level is $27 \mathrm{mg} \mathrm{l}^{-1}$ or above. The steady state, or the optimal long-term equilibrium STP level for a field with $2 \%$ slope would be $4.9 \mathrm{mg} \mathrm{l}^{-1}$. Based on the $27 \mathrm{mg} \mathrm{l}^{-1}$ threshold and $4.9 \mathrm{mg} \mathrm{l}^{-1}$ steady state, we can conclude that the optimal policies are identical for STP levels below $27 \mathrm{mg} \mathrm{l}^{-1}$ : In each case, the optimal policy will steer the STP level towards the optimal steady state value of $4.9 \mathrm{mg}^{-1}$. As gypsum application is not optimal below $27 \mathrm{mg} \mathrm{l}^{-1}$, for STP values below this threshold the values of the two policies coincide. In other words, there is no value to have the option of gypsum amendment if the optimal long-term policy will never use the option. Figure 3 illustrates this effect. The value functions pertaining to the choice sets (1) and (2) are identical up to the value of $27 \mathrm{mg} \mathrm{l}^{-1}$. Beyond the $27 \mathrm{mg} \mathrm{l}^{-1}$ STP threshold the value functions diverge; the differences in the value functions are clearly visible for STP levels beyond $30 \mathrm{mg} \mathrm{l}^{-1}$. At the STP level of $40 \mathrm{mg} \mathrm{l}^{-1}$ the difference is already substantial.

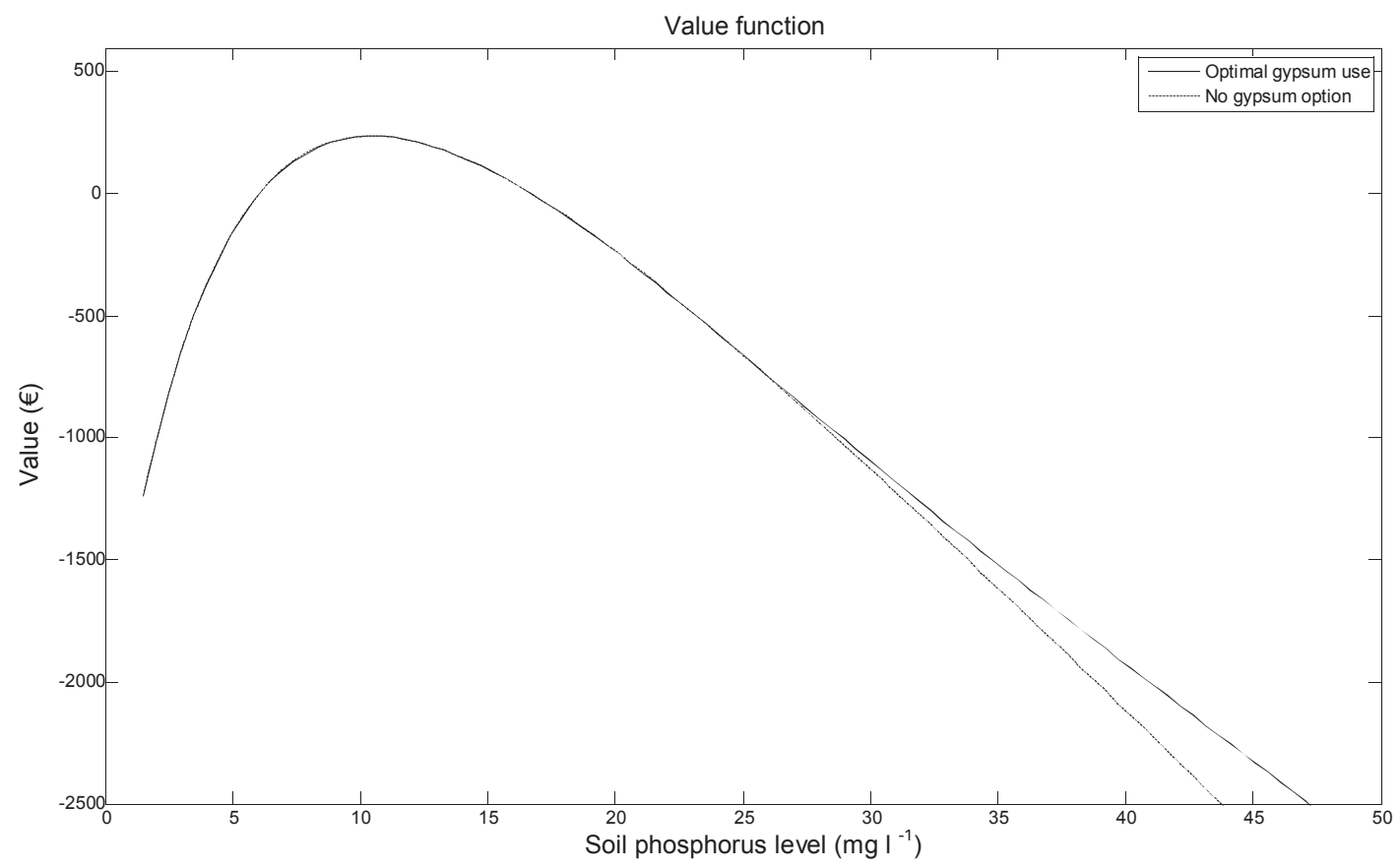

Fig. 3. Value functions for optimal policies with or without gypsum 
There is a clear interpretation for the difference in the two value functions: it is the value of having the option to use gypsum. For fields with high STP values it would be socially valuable to be able to cut down the phosphorus loads by applying gypsum. However, gypsum would not be applied permanently in the economically optimal solution. Instead, the economically optimal solution would also gradually deplete the STP reserve through adjusting fertilizer application. Once the STP level would be reduced to below $27 \mathrm{mg} \mathrm{l}^{-1}$, it would be optimal to cease applying gypsum. All this is accounted for in the value function.

The value function obtains negative values for low and high STP levels. Here, the value function depicts the value of grain production to the society on the whole. It captures both the profit from crop production and the environmental damage from phosphorus loading, in the absence of land-area based government payments to farmers. Finland's climate is harsh and average grain yields reach only about half of the levels observed in more southern European countries. Consequently, government payments form a substantial part of farm income. As our analysis focuses on the intensive margin decisions of fertilizer and gypsum application, we do not consider government payments to farmers. The negative values in Figure 3 indicate that from the point of view of the society, grain farming would not be profitable at very low STP levels, due to low yields, or at very high STP levels, due to significant environmental damage offsetting the profits from grain production.

\section{The economically optimal mix of phosphorus mitigation measures: gypsum amendment, vegetative filter strips and adjustment of fertilization to crop need}

We next examine how gypsum application interacts with another key phosphorus mitigation measure, vegetative filter strips, in an optimal policy combination. We determine the optimal filter strip width in conjunction with the optimal gypsum amendment decision (the dynamic programming solution is presented in the Appendix). The scientific motivation for considering vegetative filter strips (VFS) as erosion control measure lies in Finland's geography, which is characterized by exceptionally numerous lakes. Inland lakes cover about $10 \%$ of the total surface, and drainage waters from about $87 \%$ of agricultural land are led to lakes or rivers (Puustinen et al. 1994). Moreover, runoff volumes can be marked, as annual precipitation exceeds annual evaporation and the climate is characterized by irregular rains caused by rapid changes in the weather. These features make vegetative filter strips an important measure to mitigate phosphorus loading through eroded material contained in field runoff. We also include the optimal adjustment of fertilizer application rates in the set of phosphorus mitigation measures. The retaining of particulate phosphorus by vegetative filter strips is adopted from Lankoski et al. (2006) who calibrate their abatement function using results from Uusi-Kämppä and Kilpinen (2000). The annualized costs are as in Iho and Laukkanen (2012).

Figure 4 depicts the optimal interaction of adjusting phosphorus fertilization, VFSs and gypsum amendment for an averagely sloped field parcel (2\% slope) and with the marginal damage from phosphorus loading set at $151 € \mathrm{~kg}^{-1}$. The lefthand panel displays the optimal fertilization rate as a function of the current STP level. For soil phosphorus levels below the steady state STP $4.9 \mathrm{mg} \mathrm{l}^{-1}$, the annual phosphorus fertilization rate is high, up to $42 \mathrm{~kg} \mathrm{ha}^{-1}$, in order to quickly build up the STP. Once the steady state STP level is approached, annual fertilization rate quickly falls towards the steady state value. Similarly, for elevated STP levels, above $15 \mathrm{mg} \mathrm{l}^{-1}$, fertilization is practically ceased to allow the STP reserve to be depleted towards the steady state. The middle panel displays the optimal VFS policy. It is apparent in the figure that the VFS costs are driven by the opportunity cost of land, which, in turn, is linked to the prevailing STP level: The higher the STP, the more valuable the land (other things equal), and the more costly it is to allocate it away from production. Therefore, we observe narrower optimal VFS for higher STP levels. A crucial factor driving this result is that VFSs do not abate dissolved phosphorus, and that the losses of particulate phosphorus are not related to STP levels in the present model. These effects determine the curvature seen in the middle panel. Overall, the VFS is very narrow for the moderately sloped field. When interpreting this result one should bear in mind that the present model only accounts for the effect of VFS on phosphorus loading. Accounting for the impacts of VFS on nitrogen loads and biodiversity would increase the optimal VFS width. Finally, the righthand panel displays the optimal gypsum application policy as a function of STP level. Comparison of the middle and righthand panels shows how the optimal VFS and gypsum amendment policies are connected: As gypsum amendment becomes part of the optimal policy mix, the optimal filter strip width in turn becomes narrower, as indicated by the discrete jump in the optimal filter strip width at the STP level of about $27 \mathrm{mg} \mathrm{l}^{-1}$. That is, there is a substitution effect in the optimal policy mix: applying gypsum enables allocating more land to production. 

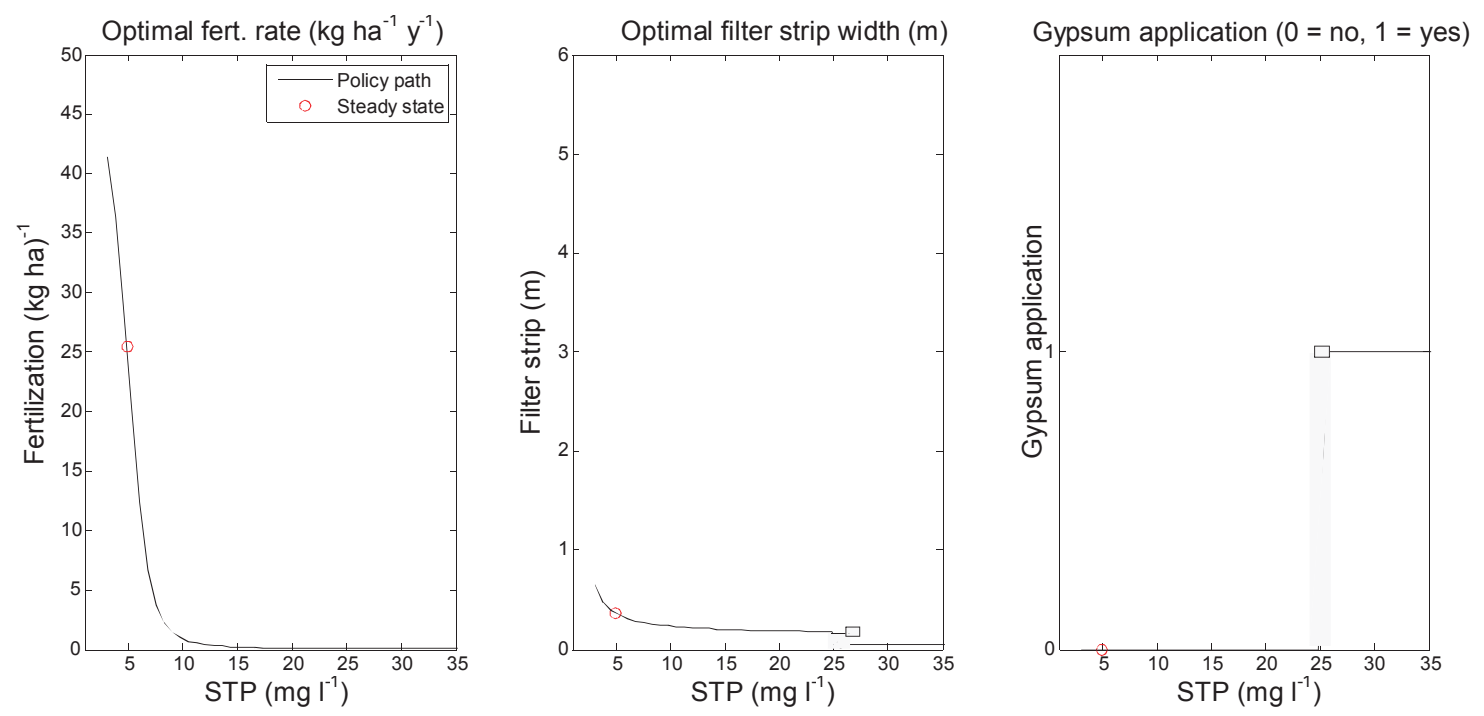

Fig. 4. Gypsum application as a part of optimal policy mix for a field parcel with $2 \%$ slope.

Figure 4 also shows that the optimal fertilization rate is not affected by gypsum application. That is, optimally adjusting fertilization based on the current STP level remains a crucial element in optimal agri-environmental policy design, whether or not gypsum amendment is included in the policy mix. Excessively high STP levels should be depleted as fast as possible, in practice without any phosphorus fertilization, regardless of the option to cut down phosphorus loads through gypsum amendment. Phosphorus fertilization becomes economically justified, from the point of view of the society on the whole, only after reaching an STP level that is fairly close to the optimal steady state value - fertilization is notably above zero only for STP levels below $15 \mathrm{mg} \mathrm{l}^{-1}$.

\section{Comparison to Finland's water protection targets}

Among the model parameters the marginal damage from phosphorus loading is the most difficult one to pin down in an unambiguous way. Several valuation studies have addressed the value of water quality improvements in the Baltic Sea region (e.g. Söderqvist 1996, 1998, Markowska and Zylicz 1999, Kosenius 2010, Vesterinen et al. 2010). In deriving our damage estimate we used the valuation results that in our opinion could be linked to phosphorus load reductions in the most transparent way. However, other choices could also have been motivated. One way to put the marginal damage estimates employed in our analysis to context is to examine what kind of an overall agricultural water protection target the damage estimate would imply. To this end, we compared the optimal outcome produced by our more conservative marginal damage estimate, $151 € \mathrm{~kg}^{-1}$, and Finland's water protection policy target. We parameterized the STP level at $14.9 \mathrm{mg} \mathrm{l}^{-1}$, the average for our study region, the Uusimaa and Varsinais-Suomi provinces, in the period 2001-2005 (data from Viljavuuspalvelu Oy). ${ }^{16}$ Unfortunately no data specific to our study region are available for field slope, and we therefore set the slope at $2 \%$, the average for Finland (Puustinen et al. 1994). We think that this is a reasonably good approximation in that the topography of agricultural land in Finland does not vary much across regions. We then computed the phosphorus load reduction that the optimal policy would produce in the first ten years. Following the optimal phosphorus abatement policy, when starting from year 2005, would provide a $25 \%$ reduction in the annual phosphorus load by year 2015 . Finland's Water Protection Policy Outlines to Year 2015 in turn state that Finland's aim is to reduce agricultural nutrient loading by $30 \%$ from the average level in $2001-2005$ by year 2015 . As our model parameterization yields a $25 \%$ reduction in average conditions in the same time frame, the marginal damage estimate employed in the analysis can be interpreted to capture the preferences underlying the Water Protection Policy Outlines quite well. ${ }^{17}$

\footnotetext{
${ }^{16}$ Viljavuuspalvelu Oy (Soil Testing Service Ltd. in English) is a commercial soil test laboratory and the market leader in soil testing in Finland. Soil testing is required for farms participating in the Finnish agri-environmental program. As over $90 \%$ of Finnish farms participate in the program, the soil test data provided by Viljavuuspalvelu Oy provide a reasonable coverage of Finnish agricultural land.

${ }^{17}$ Using the alternative marginal damage estimate, $219 € \mathrm{~kg}^{-1}$, the reduction would have been only slightly higher. The policy paths are nearly identical for the first ten years in both cases.
} 


\section{Conclusions and policy implications}

An interesting feature of gypsum amendment as a way to reduce phosphorus loads from agricultural land is that it abates both dissolved and particulate phosphorus. Furthermore, as a measure it is technically simple, it does not interfere with crop yield (Kari Ylivainio, MTT Agrifood Research Finland, personal communication), and it is familiar to farmers in that the machinery and application method are the same as for lime amendment. However, while gypsum amendment does not interfere with crop yield, it does bear a cost, comprising of the costs of the product itself, freight, and application. This study assessed the economic feasibility of gypsum amendment as a water protection measure from the point of view of the society on the whole. The results indicate that when economic factors are taken into consideration, gypsum amendment as a water protection measure is best suited for environmentally sensitive conditions, with above average field slope and STP level. The optimal use of phosphorus fertilization over time and the depletion of high soil phosphorus reserves also remain important phosphorus load mitigation measures, whether or not gypsum amendment is adopted.

The environmental benefits of gypsum amendment are a public good enjoyed by the society on the whole, but it will not be at an individual farmer's interest to bear the cost of gypsum amendment without incentives created through agri-environmental policy. Homogeneity of the costs of gypsum amendment has an interesting implication for policy design: because the costs are identical across farms, optimal incentives are identical as well. An optimal subsidy level that would encourage farms to adopt gypsum amendment would be easy to determine - the optimal subsidy would be set marginally above the cost of gypsum amendment. In theory, all farms would then be willing to adopt the measure. However, the optimization analysis indicates that the economic feasibility of gypsum amendment from the point of view of the society on the whole depends on the marginal benefit of load reductions as well as on field STP level and erosion susceptibility. How to efficiently allocate the measure to fields and farms should then also be addressed. In the case of our study area, retention is minor and most of the agricultural phosphorus loading finds its way into the Gulf of Finland or the Archipelago Sea. Uniform marginal benefit of load reductions in the study region thus provides a reasonable approximation. If field slopes and STPlevels were known to policy administrators, allocation would be straightforward. The thresholds in Figure 1 could be used to determine eligibility for the subsidy: All field parcels characterized by a slope and STP level above the threshold levels would be eligible for the subsidy, and would adopt the measure. However, acquiring the required information on field slope and STP level would also bear a cost, which we have not accounted for in the present analysis. Furthermore, where the retention rates or marginal benefits of load reductions in the receiving body of water differ, policy administrators would have to acquire location-specific information on retention and marginal benefits as well.

A concern to be born in mind would be the pricing of gypsum. Here, we have assumed gypsum to be priced at the marginal cost of production. However, gypsum is produced as a by-product of phosphorus fertilizer, and not all reserves provide gypsum that would be suitable for field gypsum amendment. Transporting gypsum over long distances could also prove prohibitively costly. Thus, the production side could potentially exhibit market power, which should be taken into account if designing a support scheme to encourage gypsum amendment as a water protection measure.

\section{Acknowledgements}

This research was carried out as part of the multidisciplinary research project TraP: Gypsum based products in reducing agricultural phosphorus loading. We thank TEKES and Yara Finland for funding. We also thank project partners, in particular Petri Ekholm, Liisa Pietola, Sirkka Tattari, Eila Turtola and Risto Uusitalo; as well as Larry Karp and Kyösti Pietola for constructive comments on model development. We would also like to thank two anonymous referees for helpful comments and suggestions that substantially improved the paper. This research was carried out while Laukkanen was at MTT Agrifood Research Finland.

\section{References}

Dillaha, T.A., Reneau, R.B., Mostaghimi, S. \& Lee, D. 1989. Vegetative Filter Strips for Agricultural Nonpoint Source Pollution Control. Transactions of the ASEA 32(2): 513-519.

Ekholm, P. \& Krogerus, K. 2003. Determining algal-available phosphorus of differing origin: routine phosphorus analyses versus algal assays. Hydrobiologia 492: 29-42. 
Ekholm, P., Turtola, E., Grönroos, J., Seuri, P. \& Ylivainio, K. 2005. Phosphorus Loss from Different Farming Systems Estimated from Soil Surface Phosphorus Balance. Agriculture, Ecosystems and Environment 110: 266-278.

Ekholm, P., Valkama, P., Jaakkola, E., Kiirikki, M., Lahti K. \& Pietola, L. 2012. Gypsum amendment of soils reduces phosphorus losses in an agricultural catchment." Agricultural and Food Science 21: 279-291.

Goetz, R.-U. \& Keusch, A. 2005. Dynamic efficiency of soil erosion and phosphorus reduction policies combining economic and biophysical models. Ecological Economics 52: 201-218.

Goetz, R.-U. \& Zilberman, D. 2000. The dynamics of spatial pollution: the case of phosphorus runoff from agricultural land. Journal of Economic Dynamics and Control 24:143-163.

Griffin, R.C. \& Bromley, D.W. 1982. Agricultural runoff as a non-point externality: theoretical development. American Journal of Agricultural Economics 64: 547-552.

HELCOM. 2010. The Extended Summary of the Main Results of the Fifth Pollution Load Compilation (Draft May 7, 2010). Cited 28 November 2011. Available on the Internet: http://www.helcom.fi/stc/files/Moscow2010/PLC_summary.pdf.

Hooda, P., Truesdale, V., Edwards, A., Withers, P., Aitken, M., Miller, A. \& Rendell, A. 2001. Manuring and Fertilization Effects on Phosphorus Accumulation in Soils and Potential Environmental Implications. Advances in Environmental Research 5: 13-21.

Horan, R. \& Ribaudo, M. 1999. Policy objectives and economic incentives for controlling agricultural sources of nonpoint pollution. Journal of the American Water Resources Association 35: 1023-1035.

Iho, A. \& Laukkanen, M. 2012. Precision phosphorus management and agricultural phosphorus loading. Ecological Economics 77: 91-102.

Koikkalainen, K., Haataja, K. \& Aakkula, J. 1999. The Impact of Agri-Environmental Support on Farm Profitability. (In Finnish). In: Agricultural Economics Research Center Publications Issue 90: An Economic Analysis of the Finnish Agri-Environmental Policy in 1995-1999. p. 78-132.

Kosenius, A.-K. 2010. Heterogeneous preferences for water quality attributes: the case of eutrophication in the Gulf of Finland, the Baltic Sea. Ecological Economics 69: 528-538.

Lankoski, J., Ollikainen, M. \& Uusitalo, P. 2006. No-till technology: benefits to farmers and the environment? Theoretical Analysis and application to Finnish agriculture. European Review of Agricultural Economics 33(2): 193-221.

Lee, K.-H., Isenhart, T.M., Schultz, R.C. \& Mickelson, S.K. 2000. Multispecies Riparian Buffers Trap Sediment and Nutrients during Rainfall Simulations. Journal of Environmental Quality 29: 1200-1205.

Markowska, A. \& Zylicz, T. 1999. Costing an International Public Good: the Case of the Baltic Sea. Ecological Economics 30: 301-316.

Miranda, J.M. \& Fackler, P.L. 2002. Applied Computational Economics and Finance. Cambridge: MIT Press. 510 p.

Myyrä, S., Pietola, K. \& Yli-Halla, M. 2007. Exploring Long-Term land Improvements under Land Tenure Insecurity. Agricultural Systems 92: 63-75.

OECD. 1982. Eutrophication of waters. Monitoring, assessment and control. Organisation for Economic Co-operation and Development, Paris.

Palva, R. 2003. "Vegetative Filter Strip Maintenance." (In Finnish). Agricultural Bulletin 4/2003 (555). Work Efficiency Institute, Helsinki, Finland.

Pentti, S. \& Laaksonen, K. 2005. "Machinery Costs and Statistical Contractor Prices." (In Finnish). Agricultural Bulletin 4/2005 (577). Work Efficiency Institute, Helsinki, Finland.

Pitkänen, H., Kiirikki, M., Savchuk, O., Räike, A., Korpinen, P. \& Wulff, F. 2007. Searching Efficient Protection Strategies for the Eutrophied Gulf of Finland: The Combined Use of 1D and 3D Modeling in Assessing Long-term State Scenarios with High Spatial Resolution. Ambio 36(2-3): 272-279.

Pote, D.H. Daniel, T.C. Sharpley, A.N. Moore, Jr. P.A. Edwards, D.R. \& Nichols, D.J. 1996. Relating Extractable Soil Phosphorus to Phosphorus Losses in Runoff. Soil Science Society of America Journal 60: 855-859.

Puustinen, M., Merilä, E., Palko, J. \& Seuna, P. 1994. "Drainage Status, Cultivation Practices and Factors Affecting Nutrient Loading from Finnish Fields." (In Finnish). Publications of the National Board of Waters and the Environment, Series A (198). National Board of Waters and the Environment, Finland.

Puustinen, M., Koskiaho, J. \& Peltonen, K. 2005. Influence of cultivation methods on suspended solids and phosphorus concentrations in surface runoff on clayey sloped fields in boreal climate. Agriculture, Ecosystems and Environment 105: 565-579.

Puustinen, M., Turtola, E., Kukkonen, M., Koskiaho, J., Linjamaa, J., Niinioja, R. \& Tattaria, S. 2010. VIHMA-A tool for allocation of measures to control erosion and nutrient loading from Finnish agricultural catchments. Agriculture, Ecosystems \& Environment 138 (3-4): 306-317

Rankinen, K., Ekholm, P, Sjöblom, H., Rita, H. \& Vesikko, L. 2010. Material fluxes in river basins and their determinants. In: Aakkula, J., Manninen, T. \& Nurro, M. (eds.) Follow-up Study on the Impacts of Agri-Environment Measures (MYTVAS 3) - Mid-term Report. (In Finnish with extended English summary). Reports of the Ministry of Agriculture and Forestry 1.

Rekolainen, S., Pitkänen, H., Bleeker, A. \& Felix, S. 1995. "Nitrogen and phosphorus fluxes from Finnish agricultural areas to the Baltic Sea." Nordic Hydrology 26 : 55-72.

Rodhe, W. 1969 Crystallization of eutrophication concepts in North Europe. In: Eutrophication, causes, consequences, correctives. National Academy of Sciences, Washington, DC, Standard Book Number 309-01700-9, p. 50-64.

Saarela, I., Järvi, A., Hakkola, H. \& Rinne, K. 1995. "Field Trials on Fertilization 1977-1994." (In Finnish). Agrifood Research Finland Bulletin No. 16. Agrifood Research Finland, Jokioinen, Finland. 
Schmitt, T., Dosskey, M. \& Hoagland, K. 1999. Filter Strip Performance and Processes for Different Vegetation, Widths, and Contaminants. Journal of Environmental Quality 28: 1479-1489.

Schnitkey, G.D. \& Miranda, M.J. 1993. The Impact of Pollution Controls on Livestock-Crop Producers. Journal of Agricultural and Resource Economics 18(1): 25-36.

Schroeder, P. D. Radcliffe, D. E. Carbera, M. L. \& Belew, C. D. 2004. Relationship between soil test phosphorus and phosphorus in runoff: effects of soil series variability. Journal of Environmental Quality 33: 1452-1463.

Sharpley, A.N. \& Rekolainen, S. 1997. Phosphorus in agriculture and its environmental implications. In: Tunney, H., Carton, O.T., Brookes, P.C. \& Johnson, A.E. (eds). Phosphorus losses from soil to water. Cambridge: CAB International, UK. p. 1-54.

Shortle, J.S. \& Abler, D.G. 1999. Agriculture and the environment. In: van den Bergh J. (ed.) Handbook of Environmental and Resource Economics. Cheltenhamn: Edward Elgar. p. 159-176.

Shortle, J.S. \& Dunn, J.W. 1986. The relative efficiency of agricultural source water pollution control policies. American Journal of Agricultural Economics 68: 668-677.

Söderqvist, T. 1996. Contingent Valuation of a Less Eutrophicated Baltic Sea. Beijer Discussion Papers Series No. 88, Stockholm, Sweden.

Söderqvist, T. 1998. Why Give up Money for the Baltic Sea? Motives for People's Willingness (or Reluctance) to Pay. Environmental and Resource Economics 12, 249-254.

Söderqvist, T. \& Scharin, H. 2000. The regional willingness to pay for a reduced eutrophication in the Stockholm archipelago. Beijer Discussion paper No. 128.

Solow, A. 2000. Red tides and dead zones: eutrophication in the marine environment. In: US Policy and the global environment: Memos to the president. The Aspen Institute, Aspen, Colorado.

Tamminen, T. \& Andersen, T. 2007. Seasonal phytoplankton nutrient limitation patterns as revealed by bioassays over Baltic Sea gradients of salinity and eutrophication. Marine Ecology Progress Series 340: 121-138.

Uusi-Kämppä, J. \& Kilpinen, M. 2000. Buffer strips for reducing nutrient loading. (In Finnish). Agricultural Research Center Publications 83.

Uusitalo, R. \& Jansson, H. 2002. "Dissolved Reactive Phosphorus in Runoff Assessed by Soil Extraction with an Acetate Buffer." Agricultural and Food Science in Finland 11: 343-353.

Uusitalo, R., Ekholm, P., Turtola, E., Pitkänen, H., Lehtonen, H., Granlund, K., Bäck, S., Puustinen, M., Räike, A., Lehtoranta, J., Rekolainen, S., Walls, M. \& Kauppila, P. 2007a. "Agriculture and Baltic Sea Eutrophication." (In Finnish). Agriculture and Food Production 96, Agrifood Research Finland. Jokioinen, Finland.

Uusitalo, R., Turtola, E., Grönroos, J., Kivistö, J., Mäntylahti, V., Turtola, A., Lemola, R. \& Salo, T. 2007b. Finnish trends in phosphorus balances and soil test phosphorus. Agricultural and Food Science 16:301-316.

Uusitalo, R., Ylivainio, K., Hyväluoma, J., Rasa, K., Kaseva, J., Nylund, P., Pietola, L. \& Turtola, E. (2012). The effects of gypsum on the transfer of phosphorus and other nutrients through clay soil monoliths. Agricultural and Food Science 21: 260-278.

Vesterinen, J., Pouta, E., Huhtala, A. \& Neuvonen, M. 2010. Impacts of changes in water quality on recreation behavior and benefits in Finland. Journal of Environmental Management 91: 984-994.

Wischmeier, W.H. \& Smith, D.D. 1978. Predicting Rainfall Erosion Losses. Washington D.C: U.S. Department of Agriculture, Agricultural Handbook 537. 
Appendix. Optimal vegetative filter strip width, gypsum amendment and fertilizer application decisions.

We use the same empirical specification of the impacts of vegetative filter strips (VFS) on PP load as Iho and Laukkanen (2012). Below, we describe the empirical specification only briefly; for a more detailed discussion and references, we refer the reader to Iho and Laukkanen (2012). First, we note that VFSs filter eroded materials from runoff and set erodible land away from production; that they do not affect DRP; no P loss occurs from land under VFS; and VFSs retain PP from surface runoff only. Furthermore, for simplicity, we abstract away from the impact of VFS on the development of the average STP of the field parcel; thus, the state transition function remains $s_{t+1}=\Gamma\left(s_{t}, x_{t}\right) .{ }^{18}$

Including VFS in the model introduces a third choice variable, here the VFS width, $v_{t}$. As we consider a square shaped parcel of one hectare size, the unit used for VFS width is hectometer (100 meters), and VFS width is constrained by $0 \leq v_{t} \leq 1$. The VFS width coincides with the share of the parcel allocated to the VFS. Vegetative filter strips remove a proportion of the field parcel from production and therefore affect per hectare profits from production, which now are $\left\{\left[p Y\left(s_{t}, x_{t}\right)-w x_{t}-r\right]-g a_{t}\right\}\left(1-v_{t}\right)$. As VFS have been shown to reduce $P P$ load while no significant impact has been found on DRP load, $v_{t}$ enters the expression for PP load, which now reads $L_{P P}\left(v_{t}\right)$. Summing up, with VFS included in the model, the per-period, per-hectare social net return from crop production is

$$
\begin{aligned}
\Pi\left(s_{t}, x_{t}, a_{t}, v_{t}\right) & =\left\{\left[p Y\left(s_{t}, x_{t}\right)-w x_{t}-r\right]-g a_{t}\right\}\left(1-v_{t}\right)-C\left(v_{t}\right) \\
- & m\left[\left(1-a_{t} T_{D R P}\right) L_{D R P}\left(s_{t}\right)+\left(1-a_{t} T_{P P}\right) L_{P P}\left(v_{t}\right)\right]\left(1-v_{t}\right)
\end{aligned}
$$

The Bellman equation corresponding to equation (3) now reads

$$
V\left(s_{t}\right)=\max _{\substack{0 \leq a_{t} \leq 1 \\ 0 \leq x_{t} \\ 0 \leq v_{t} \leq 1}}\left\{\Pi\left(s_{t}, x_{t}, a_{t}, v_{t}\right)+\beta V\left(s_{t+1}\right)\right\}
$$

Acknowledging the constraints $0 \leq a_{t} \leq 1,0 \leq x_{t}$ and $0 \leq v_{t} \leq 1$, the first order conditions to the problem are

$$
\begin{aligned}
& \Pi_{a}\left(s_{t}, a_{t}, x_{t}, v_{t}\right)+\beta \lambda\left(s_{t+1}\right) \Gamma_{a}\left(s_{t}, x_{t}\right)=\mu_{a t} \\
& \Pi_{x}\left(s_{t}, a_{t}, x_{t}, v_{t}\right)+\beta \lambda\left(s_{t+1}\right) \Gamma_{x}\left(s_{t}, x_{t}\right)=\mu_{x t} \\
& \Pi_{v}\left(s_{t}, a_{t}, x_{t}, v_{t}\right)+\beta \lambda\left(s_{t+1}\right) \Gamma_{v}\left(s_{t}, x_{t}\right)=\mu_{v t}
\end{aligned}
$$

In addition to (A3), $a_{t}, x_{t}, v_{t}, \mu_{a t}, \mu_{x t}$ and $\mu_{v t}$ have to satisfy the complementarity conditions

$$
\begin{aligned}
& a_{t}>0 \Rightarrow \mu_{a t} \geq 0 ; \quad a_{t}<1 \Rightarrow \mu_{a t} \leq 0 ; \\
& x_{t}>0 \Rightarrow \mu_{x t}=0 ; \\
& v_{t}>0 \Rightarrow \mu_{v t} \geq 0 ; v_{t}<1 \Rightarrow \mu_{v t} \leq 0 ;
\end{aligned}
$$

Consider first the optimal share of the field parcel to be treated with gypsum, $a_{t}$. The per period net return $\Pi\left(s_{t}, x_{t}, a_{t}, v_{t}\right)$ remains linear in $a_{t}$, and the marginal impact of $a_{t}$ on $\Pi\left(s_{t}, x_{t}, a_{t}, v_{t}\right)$ will be either positive, negative, or zero for all $a_{t}$ : either

$$
\Pi_{a}=\left(-g+m\left[T_{D R P} L_{D R P}\left(s_{t}\right)+T_{P P} L_{P P}\right]\right)\left(1-v_{t}\right)>0
$$

$$
\Pi_{a}=\left(-g+m\left[T_{D R P} L_{D R P}\left(s_{t}\right)+T_{P P} L_{P P}\right]\right)\left(1-v_{t}\right)<0, \text { or }
$$

$$
\Pi_{a}=\left(-g+m\left[T_{D R P} L_{D R P}\left(s_{t}\right)+T_{P P} L_{P P}\right]\right)\left(1-v_{t}\right)=0 \text { for all } a_{t} .
$$

As before, the optimal $a_{t}$ will be a boundary one. Furthermore, we see that $v_{t}$ has no impact on the optimal choice of $a_{t}$ (as long as the optimal $v_{t}$ is less than 1 ).

\footnotetext{
${ }_{18}$ Iho and Laukkanen (2012) took this effect into account. Quantitatively the impact of VFS on the average STP level of the field parcel was minor.
} 
Consider next the optimal fertilization rate, $x_{t}$. The optimal choice of $x_{t}$, for a given soil phosphorus level $s_{t}$, is determined by the first-order condition

$$
\begin{aligned}
& {\left[p Y_{x}\left(s_{t}, x_{t}\right)-w\right]\left(1-v_{t}\right)+\beta \lambda\left(s_{t+1}\right) \Gamma_{x}\left(s_{t}, x_{t}\right)=\mu_{x t} ;} \\
& x_{t}>0 \Rightarrow \mu_{x t}=0 .
\end{aligned}
$$

The first order condition for VFS becomes:

$$
\begin{aligned}
& -\left[p Y\left(s_{t}, x_{t}\right)-w x_{t}-r-g a_{t}\right]-C_{v}\left(v_{t}\right)-m\left(1-a_{t} T_{P P}\right) L_{p P, v}\left(v_{t}\right)+\beta \lambda\left(s_{t+1}\right) \Gamma_{v}\left(s_{t}, x_{t}\right)=\mu_{v t} \\
& v_{t}>0 \Rightarrow \mu_{v t}=0, v_{t}<1 \Rightarrow \mu_{v t} \leq 0 ;
\end{aligned}
$$

Here, $C_{v}\left(v_{t}\right)$ and $L_{P P, v}\left(v_{t}\right)$ are the derivatives of the VSF cost and PP load with respect to $v_{t}$.

The envelope theorem applied to the same problem implies

$$
\lambda\left(s_{t}\right)=\left[p Y_{s}\left(s_{t}, x_{t}\right)\right]\left(1-v_{t}\right)-m\left(1-a_{t} T_{D R P}\right) L_{D R P, s}\left(s_{t}\right)\left(1-v_{t}\right)+\beta \lambda\left(s_{t+1}\right) \Gamma_{s}\left(s_{t}, x_{t}\right)
$$

We next describe the empirical effect of VFS on PP loss. We interpret the last term in equation (11) as PP load in drainage, which should be independent of field slope. Accordingly, the bioavailable PP loss via surface runoff is given by $L_{P P S u r f a c e}(\gamma)=b\left(\alpha_{1}^{P P} \gamma^{2}+\alpha_{2}^{P P} \gamma\right)$ and PP load via drainage by $L_{P P D \text { rainage }}=\alpha_{3}^{P P}$.

Following Lankoski et al. (2006), the retaining of PP by filter strips is described by the function

$$
R(v)=v^{0.3} L_{\text {PPSurface }}
$$

The total bioavailable PP loss is then given by

$$
L_{P P}(v)=b(1-v)(1-R(v)) L_{P P S u r f a c e}(\gamma)
$$

